\title{
Boston Consulting Group Sebagai Dasar Strategi pada Pabrik Gula Candi Baru Sidoarjo
}

Dwi Syahfitri*a, Eko Nurhadia, Indra Tjahaja Amira

a Fakultas Pertanian, Universitas Pembangunan Nasional "Veteran" Jawa Timur

*Corresponding author : dwisyahfitri12@gmail.com

\section{Article Info}

Article history:

Received 8 April 2021

Received in revised from 18 April 2021

Accepted 12 July 2021

DOI:

https://doi.org/10.32938/ag.v6i3.1357

Keywords:

Sugar Factory

Strategy

$B C G$

\begin{abstract}
Abstrak
PG Candi Baru Sidoarjo is experiencing increasing competition from within the country and abroad to enter the global market in the sugar industry as seen from the increase in sugar, which has increased by $18.97 \%$ or 5.03 million tons / year. The existence of such competitive conditions will certainly have implications so it is necessary to know in advance the position of market growth in order to formulate the right strategy for the company. The research method is descriptive quantitative with calculations from the Boston Consulting Group. The results show that the position of the PG Candi Baru Sidoarjo market growth matrix is in the question mark quadrant position with the type of business that has a low market share, but has high market growth prospects with an acquisition value of $0.094<1$.
\end{abstract}

\section{Pendahuluan}

Komoditi gula Indonesia yang diproduksi di dalam negeri selalu mengalami fluktuatif, dan cenderung meningkat dalam produksinya namun kebutuhan gula di dalam negeri setiap tahunnya mengalami peningkatan. Indonesia masih belum bisa mencukupi kebutuhan gula, baik untuk konsumsi langsung maupun pasokan kepada industri dari produksi gula dalam negeri. Untuk menutupi kekurangan tersebut dipasok dari impor. Menurut Trikuntari et al. (2020), Impor gula Indonesia mengalami peningkatan rata-rata $18,97 \%$ per tahun. Impor gula pada tahun 2014 sebesar 2,97 juta ton dan meningkat menjadi 5,03 juta ton pada 2018. PG Candi Baru Sidoarjo merupakan salah satu perusahaan telah berdiri sejak tahun 1832. PG Candi Baru Sidoarjo menghasilkan gula pasir berjenis Superior Hooft Suiker (SHS) IA. PG Candi Baru Sidoarjo mengalami tuntutan persaingan yang semakin kompetitif dikarenakan banyaknya pesaing dari dalam negeri maupun luar negeri untuk memasuki pasar global dengan kualitas rendemen yang baik dengan harga relatif lebih terjangkau yang akan menciptakan situasi persaingan semakin ketat dalam industri gula. Adanya kondisi persaingan tersebut dipastikan akan berimplikasi pada PG Candi Baru Sidoarjo.

Menurut Asosiasi Petani Tebu Rakyat Indonesia APTRI Badan Kordinasi Penanaman Modal (2015), salah satu permasalahan pada persaingan gula nasional adalah rendahnya kualitas gula yang dihasilkan sehingga mempengaruhi nilai rendemen. Selain itu, harga gula yang tidak stabil menjadi salah satu pemicu berkurangnya semangat para petani tebu untuk budidaya tanaman tebu. Disamping itu, adanya lahan fiktif dan masuknya impor gula rafinasi dalam skala besar yang mengakibatkan persoalan tentang pergulaan nasional semakin kompleks. Kebijakan pemerintah yang dinilai kurang memihak pada industri gula nasional dari segi pengawasan keluar-masuknya gula impor dan penetapan harga gula nasional yang tidak sesuai dengan biaya produksi yang dikeluarkan.

Menurut Badan Koordinasi Penanaman Modal (2015), menyatakan bahwa rendahnya efisiensi pabrik yang diperburuk dengan rendahnya kualitas bahan baku tebu mengakibatkan rendahnya nilai rendemen yang diperoleh. Disamping itu, beberapa negara Asia sudah mencapai $>10 \%$ nilai rendemen, seperti halnya: Thailand 13,4\%, India 10,5\%, dan Filipina 10,4\%. Rendahnya performa rendemen selama sepuluh tahun terakhir sangat berdampak pada capaian produktivitas gula per hektar yang yang dihasilkan.

PG Candi Baru Sidoarjo merupakan salah satu perusahaan yang memproduksi gula pasir jenis Superior Hooft Suiker (SHS) IA dimana menghasilkan gula kualitas tinggi dengan menerapkan ICUSMA (International Commission for Uniform Methods of Sugar Analysis). Tetapi, PG Candi Baru Sidoarjo menghadapi persaingan yang semakin kompetitif dikarenakan meningkatnya jumlah impor yang masuk di Indonesia seiring berlakunya perdagangan bebas. Adanya persaingan tersebut dipastikan akan berimplikasi pada keberlangsungan PG Candi Baru Sidoarjo dari segi daya saing.

Untuk mengatasi masalah tersebut, PG Candi Baru Sidoarjo harus dikelola dengan benar yang tentunya akan berdampak pada terwujudnya visi misi yang menjadi tujuan perusahaan. Pemilihan strategi, PG Candi Baru Sidoarjo harus mempertimbangkan secara cermat hal-hal mengenai kekuatan-kelemahan perusahaan dan kesempatan-peluang guna mencapai tujuan 
perusahaan. Menurut Sulasih (2020), tercapainya keberhasilan perusahaan tergantung pada kemampuan perusahaan dalam menjalankan fungsi pemasaran sebagai titik fokus perusahaan.

Tabel 1. Indikator Efesiensi Industri Gula

\begin{tabular}{ccc}
\hline Indikator & Rata-rata Dunia & PG BUMN \\
\hline Produktivitas Tebu (ton/ha) & $80-90$ & 75,5 \\
Hasil Gula per Ha & $9,6-12,60$ & $4,39-6,43$ \\
Rendemen (\%) & $12-14$ & $5,8-8,5$ \\
Konsumsi Uap (\%tebu) & $<40$ & $52-60$ \\
Overall Recovery (OR) & $85-87,5$ & $70-78$ \\
\hline
\end{tabular}

Sumber: (Badan Kordinasi Penanaman Modal, 2015)

Menurut Shafira Puteri et al., (2019), posisi pertumbuhan pasar merupakan hal sangat penting dilakukan perusahaan agar bisa mempersiapkan langkah yang tepat bagi perusahaan. Disisi lain, hal ini terkadang tidak diperhatikan oleh perusahaan. Organisasi yang menggunakan boston consulting group, dapat menemukan kesuksesan dalam prosedur bisnis. Oleh karena itu, organisasi/perusahaan berpendapat bahwa boston consulting group merupakan portofolio pertumbuhan pasar yang sederhana (Saputra et al., 2020; Kader \& Hossain, 2020). Pernyataan ini didukung oleh Respati et al., (2015), mengatakan bahwa Boston Consulting Group berfungsi sebagai daya tarik industri, dan pangsa pasar dalam keunggulan kompetitif.

Strategi ini akan berjalan dengan baik bila masing-masing pihak saling menyadari kekuatan, kelemahan, ancaman dan peluang untuk saling melengkapi, saling menguatkan, dan tidak saling mengeksploitasi sehingga menciptakan keuntungan bagi perusahaan. Sebelum mengembangkan strategi pada PG Candi Baru Sidoarjo harus terlebih dahulu mengetahui posisi perusahaan dalam kuadran matriks boston consulting group, sebagai upaya atau pertimbangan dalam merumuskan strategi untuk mempertahankan dan meningkatkan pangsa pasar bagi PG Candi Baru Sidoarjo.

\section{Metode}

Penelitian ini dilakuan pada PG Candi Baru Sidoarjo. Pemilihan lokasi ini berdasarkan pertimbangan bahwa PG Candi Baru Sidoarjo adalah salah satu manufaktur yang berdiri sejak tahun 1832 dengan kapasitas mesin giling sebesar 3000 TCD.

Pengambilan sampel menggunakan purposive sampling dengan pengambilan informan sumber data berdasarkan pertimbangan tertentu. Pemilihan narasumber dengan pertimbangan tertentu berdasarkan memiliki pengetahuan mengenai informasi yang dibutuhkan. Empat informan terdiri dari bagian manajer, bagian produksi, bagian penyuluh lapang dan bagian pemasaran. Analisis data yang digunakan adalah analisis Boston Consulting Group secara ilustratif menunjukkan posisi tingkat pertumbuhan dan pangsa pasar relatif pada bisnis (Sarjono et al., 2013) (Prasetyo \& Sunarti, 2016).

1. Tingkat pertumbuhan pasar (Market growth rate)

$$
\mathrm{TPP}=\frac{V P N-V P N 1}{V P N 1} X 100 \%
$$

Keterangan:

TPP $\quad=$ Tingkat pertumbuhan pasar (Rupiah)

$\mathrm{VP} \mathrm{N} \quad=$ Volume penjualan perusahaan tahun terakhir (Rupiah)

VP N1 = Volume penjualan tahun sebelumnya (Rupiah)

2. Pangsa pasar relative (Relative market share)

$$
\mathrm{PPR}=\frac{V P N}{V P P N}
$$

Keterangan:

PPR $\quad=$ Pangsa pasar relative $($ Rupiah $)$

VP N $\quad=$ Volume penjualan tahun terakhir (Rupiah)

VPP N $\quad=$ Volume penjualan tahun terakhir pesaing (Rupiah)

Menurut Rusdan (2016) dan Nugroho (2018) Matriks Boston Consulting Group (BCG), memiliki empat kuadran terdiri dari sumbu vertikal sebagai tingkat pertumbuhan dan sumbu 
horizontal merupakan pangsa pasar dengan titik tengah sumbu $\mathrm{X} 0,50$ dan sumbu $\mathrm{Y}$ dengan nilai tinggi +20 , nilai tengah 0 dan rendah -20 persen.

\section{POSISI PANGSA PASAR RELATIF}

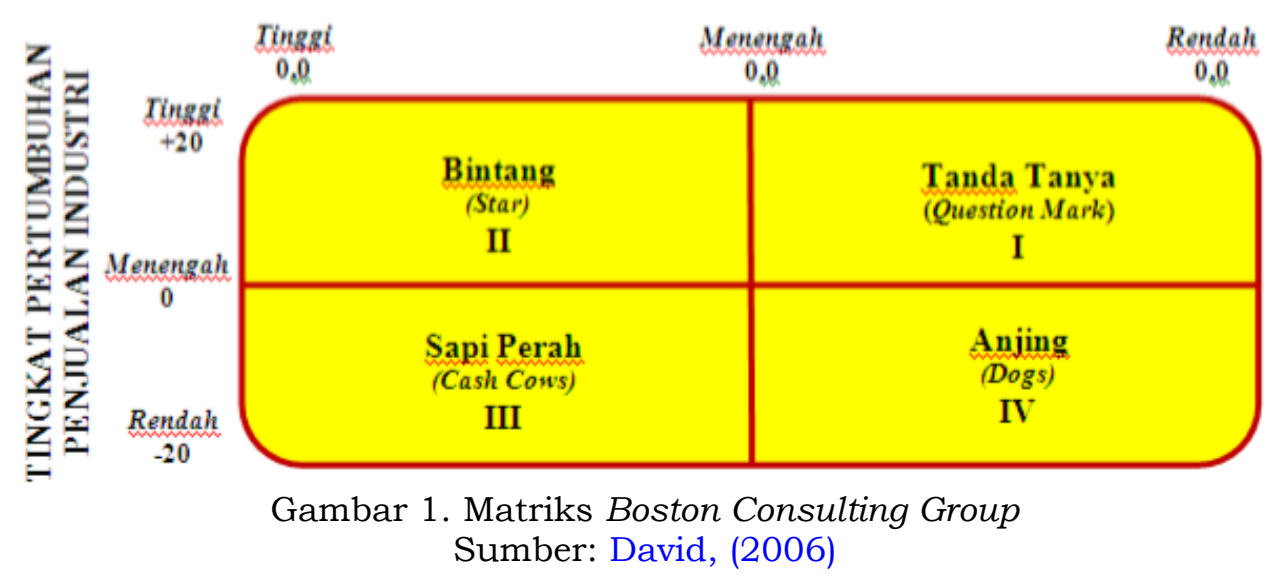

1. Tanda Tanya, pangsa pasar rendah dengan tingkat pertumbuhan pasar yang tinggi. Sebagian besar pengeluaran kas pada bisnis tergolong tinggi dan pendapatan kas yang rendah. Perusahaan harus menentukan pilihan dalam mempertahankan perusahaan dengan peninjauan kembali strategi intensif dari segi penetrasi dan pengembangan pasar atau pengembangan produk dan menjual bisnis (Maristia et al., 2020).

2. Bintang, pangsa pasar tinggi dengan tingkat pertumbuhan pasar yang tinggi. Posisi ini memiliki kecenderungan untuk mendapatkan keuntungan besar. Disamping itu, jika pangsa pasar menjadi sangat besar dan tingkat pertumbuhan pasar menurun maka posisi bintang akan berubah menjadi sapi perah (Mohajan, 2018).

3. Sapi Perah, pangsa pasar tinggi dengan tingkat pertumbuhan pasar yang rendah. Dimana sumberdaya harus dialokasikan untuk melindungi pangsa pasar dan melakukan modifikasi produk untuk mengikuti perubahan selera konsumen. Umumnya kuadran sapi perah adalah kuandran bintang di masa lalu (Hossain \& Kader, 2020).

4. Anjing, Pangsa pasar rendah dengan tingkat pertumbuhan pasar yang tidak tumbuh. Situasi ini umumnya tidak menghasilkan kas yang cukup untuk menahan pertumbuhan pasar yang relatif rendah. Jika tetap bisnis tetap berjalan maka menyebabkan pemborosan sumberdaya yang disebabkan posisi internal dan eksternal bisnis lemah. Ketika berada pada posisi ini, penghematan menjadi alternatif strategi terbaik yang dapat dijalankan agar mampu bertahan dan menguntungkan (Keelson, 2018).

\section{Hasil dan pembahasan}

\section{Pertumbuhan Pasar PG Candi Baru Sidoarjo}

Metode boston consulting group dilakukan guna mengetahui posisi pasar pada PG Candi Baru Sidoarjo dengan perhitungan tingkat pertumbuhan pasar dan pangsa pasar relatif.

1. Tingkat Pertumbuhan Pasar

Tingkat pertumbuhan pasar atau market growth merupakan total jumlah penjualan pada tahun yang terakhir dengan pengukuran persentase volume jumlah penjualan dua tahun terakhir PG Candi Baru Sidoarjo.

Berikut data jumlah penjualan yang dilakukan oleh PG Candi Baru Sidoarjo selama beroperasi pada tahun 2018 dan 2019.

Berdasarkan perhitungan diatas, diketahui bahwa pertumbuhan pasar gula untuk PG Candi Baru Sidoarjo sebesar 94\% yang artinya pertumbuhan pasar gula tergolong sangat tinggi. Permintaan gula di Indonesia setiap tahunnya mengalami peningkatan yang disebabkan oleh meningkatnya jumlah penduduk dan industri makanan dan minuman. Semakin tinggi permintaan pasar akan mempermudah PG Candi Baru Sidoarjo pada penjualan produk ataupun menciptakan pasar baru yang semakin menguntungkan bagi perusahaan.

Pernyataan ini sejalan dengan Rute et al., (2015) bahwa kebutuhan akan gula di Indonesia selalu terus meningkat seiring dengan bertambahnya jumlah penduduk dan peningkatan pendapatan sebesar $4 \%$ per tahun untuk memenuhi kebutuhan. Selain itu, pernyataan ini didukung oleh Zaini, (2008) dilihat dari sisi ekonomi dan sosial bahwa gula pasir merupakan salah satu kebutuhan pokok sehingga semakin tinggi konsumsi gula maka semakin tinggi koefisien 
elastistias permintaan walau telah terjadinya perubahan harga. Selain itu, gula sangat dibutuhkan dalam bidang industri makanan dan minuman sehingga kecenderungan elastisitas permintaan semakin tinggi.

Tabel 2. Volume Penjualan Gula tahun 2018 dan 2019

\begin{tabular}{lrr}
\hline \multicolumn{1}{c}{ Uraian } & \multicolumn{2}{c}{ Tahun } \\
\cline { 2 - 3 } & $\mathbf{2 0 1 8}$ & $\mathbf{2 0 1 9}$ \\
\hline Gula Prod. Th. Berjalan & 158.450 .083 & 310.105 .477 \\
Tetes Prod. Th. Berjalan & 19.548 .971 & 32.698 .780 \\
Persedian Gula & 4.185 .250 & 11.724 .295 \\
Persediaan tetes & 17.695 & 0 \\
Tebu Th. Berjalan & 0 & 0 \\
\hline Total & $\mathbf{1 8 2 . 2 0 1 . 9 9 8}$ & $\mathbf{3 5 4 . 5 2 8 . 5 5 2}$
\end{tabular}

Sumber: PT. Data Sekunder, 2020

$$
\begin{aligned}
T P P & =\frac{\text { Gula } 2019-\text { Gula } 2018}{\text { Gula } 2018} \times 100 \% \\
T P P= & \frac{354.528 .552-182.201 .998}{182.201 .998} \times 100 \% \\
& =0,94 \\
& =94 \% \text { (Pertumbuhan pasar tinggi) }
\end{aligned}
$$

\section{Pangsa Pasar Relatif}

Pangsa pasar relatif merupakan persentase dari penjualan PG Candi Baru Sidoarjo (dari seluruh sumber) dengan total penjualan jasa ataupun produk PG Candi Baru Sidoarjo.

Kompetitor PG Candi Baru Sidoarjo pada pemasaran gula yang berdasarkan dari wawancara adalah gula impor yang masuk di Jawa Timur. Dengan masuknya gula impor sangat mempengaruhi harga yang telah ditentukan oleh PG Candi Baru Sidoarjo berdasarkan biaya produksi yang dikeluarkan dan harga eceran tertinggi kepada konsumen.

Berikut ini disajikan data jumlah penjualan yang dilakukan oleh PG Candi Baru Sidoarjo

\begin{tabular}{|c|c|c|}
\hline PT. Pabrik Gula Candi Baru Sidoarjo & \multicolumn{2}{|c|}{ Gula Impor di Jawa Timur } \\
\hline Uraian & Uraian & Nilai CIF (\$) \\
\hline Gula Prod. Th. Berjalan & 310.105.477Thailand & 249,37 \\
\hline Tetes Prod. Th. Berjalan & 32.698.780Australia & 16,18 \\
\hline Persedian Gula & 11.724.295Total & 265,55 \\
\hline Persediaan tetes & ONilai Tukar Rupiah & 14.130 \\
\hline Tebu Th. Berjalan & 0 & \\
\hline
\end{tabular}
selama beroperasi pada tahun 2019 dan penjualan pesaing pada tahun 2019 (Badan Pusat Statistik Provinsi Jawa Timur, n.d.).

Tabel 3. Total Penjualan PG Candi Baru Sidoarjo dan Gula Impor

\section{Total}

Sumber: PT. Pabrik Gula Candi Baru Sidoarjo dan BPS Jawa Timur, 2020

$$
\begin{aligned}
P P R= & \frac{\text { Gula 2019 PG Candi Baru Sidoarjo }}{\text { Gula 2019 Impor masuk di Jawa Timur }} \\
P P R= & \frac{354.528 .552}{3.752,221.500} \\
& =0,094<1 \text { (pangsa pasar rendah) }
\end{aligned}
$$

Berdasarkan perhitungan maka diketahui bahwa pangsa pasar relatif PG Candi Baru Sidoarjo tahun 2019 sebesar 0,094 < 1 maka menunjukkan bahwa PG Candi Baru Sidoarjo tidak menguasai pangsa pasar yang lebih besar dibandingkan produk Gula Impor yang masuk di Jawa Timur yang disebabkan pangsa pasar lebih kecil dari satu. Pangsa pasar rendah diakibatkan gula nasional tidak mampu memenuhi permintaan konsumen. Hal ini sejalan dengan (Saputri, 2018) mengatakan bahwa kebutuhan gula selalu lebih besar dari produksi gula yang dihasilkan dalam negeri dengan total kebutuhan gula sebesar 5,3 juta ton dan produksi gula nasional hanya mampu menghasilkan 2,01 juta ton pertahun dan impor gula sebesar 3,29 juta ton pada tahun 2009/2010 dan 2016/2017 yang dilakukan untuk pemenuhan kebutuhan gula. 


\section{Matriks Boston Consulting Group (BCG)}

Dari perhitungan diatas, tingkat pertumbuhan pasar PG Candi Baru Sidoarjo diperoleh hasil 94\%, hal ini menunjukkan bahwa PG Candi Baru Sidoarjo memiliki tingkat pertumbuhan pasar tergolong sangat tinggi tetapi hasil perhitungan pangsa pasar relatif rendah yang diperoleh hasil 0,094 pada tahun 2019. Berdasarkan pernyataan diatas, dapat disimpulkan bahwa pasar gula di Indonesia khususnya Jawa Timur memiliki permintaan yang sangat tinggi dari segi masyarakat dan industri makanan dan minuman.

Hasil perhitungan boston consulting group dihasilkan bahwa PG Candi Baru Sidoarjo dengan gula impor yang masuk di Jawa Timur sebagai pesaing terletak pada posisi tanda tanya (Question) artinya produk atau bisnis unit yang memiliki prospek pertumbuhan pasar yang tinggi tetapi tidak mampu menguasai pasar sehingga penghasilan (pendapatan) yang diperoleh tidak sebanding dengan biaya produksi yang dikeluarkan. Disisi lain dengan pertumbuhan pasar yang tergolong tinggi sangat berpotensi untuk mendapatkan keuntungan yang besar jika dilakukannya peninjauan ulang strategi untuk tercapainya pangsa pasar yang tinggi sehingga dapat memperkuat posisi perusahaan dan berpotensi perusahaan menjadi bintang yang artinya memperoleh keuntungan yang optimal bagi perusahaan.

Menurut Siwi \& Handojo, (2019) menyatakan bahwa terjadinya ketimpangan permintaan dan penawaran/ketersediaan gula nasional yang disebabkan oleh rendahnya produktivitas tebu dan berpengaruh pada rendahnya rendemen sehingga produksi gula yang dihasilkan rendah. Selain itu, kondisi sebagian pabrik gula pada saat ini Sebagian besar tua dan tidak bisa lagi berproduksi secara efisien.

Berdasarkan dari perhitungan diatas bahwa posisi PG Candi Baru Sidoarjo pada matriks boston consulting group sebagai berikut:

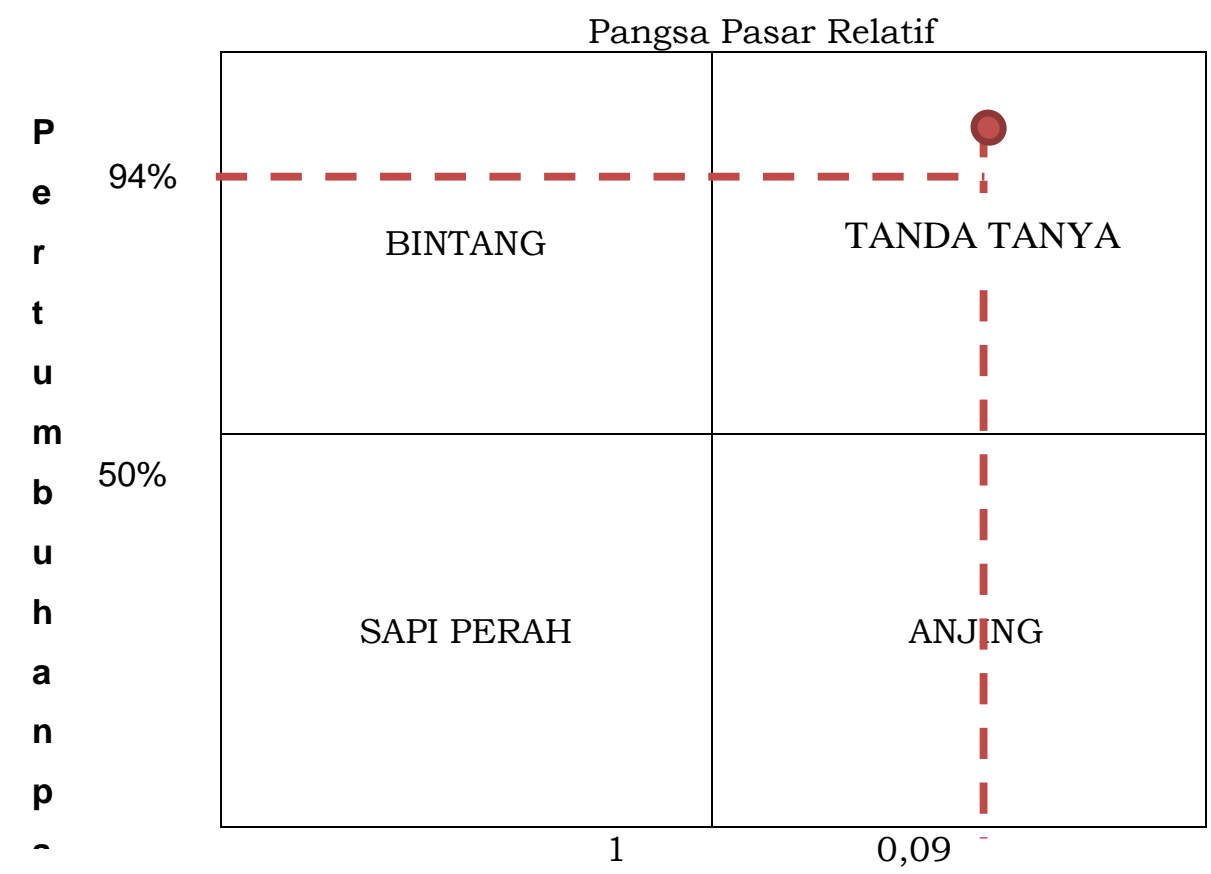

Gambar 4. Matriks Boston Consulting Group (BCG) PG Candi Baru Sidoarjo

Sumber: Data diolah, 2020

Berdasarkan kuadran pada Matriks Boston Consulting Group PG Candi Baru Sidoarjo menyatakan bahwa pasar yang terletak pada posisi tanda tanya (Question) maka dari itu untuk tercapainya pada posisi bintang (star) perlunya perluasan segmen pelanggan dengan dukungan produk yang telah memiliki standart mutu perdagangan pemberlakuan SNI dengan menerapkan penerapan ICUMSA (International Commission for Uniform Methods of Sugar Analysis) dimana menunjang produksi dalam menghasilkan gula kualitas tinggi serta kustomisasi produk dan kemasan dapat disesuaikan dengan permintaan pasar. Hal ini dapat membuat perusahaan memiliki daya tawar yang kuat sehingga mampu bersaing dan berpeluang diterima di pasar baru dengan memanfaatkan lokasi PG Candi Baru Sidoarjo yang startegis dikarenakan dekatnya akses pelabuhan maka berpeluang besar dalam mempeluas pasar dengan biaya pengiriman yang relatif terjangkau dan sumberdaya manusia yang terampil dalam memanfaatkan penggunaan teknologi karena adanya pelatihan khusus yang diberikan oleh PG Candi Baru Sidoarjo menjadi pendukung utama dalam mengembangkan perluasan pasar pada PG Candi Baru Sidoarjo. Selain perluasan 
segmen pelanggan pada produk utama, perlunya penciptaan inovasi produk untuk mencapai industri zero waste dengan mengoptimalkan pemanfaatan setiap buangan atau hasil samping dari tebu maupun proses pengolahannya dalam melakukan diversifikasi produk untuk menekan biaya produksi, memperluas pasar dan memliki pasar yang menguntungkan serta mengurangi resiko kerugian pada produk utama pada pabrik. Menurut Ristianingsih et al., (2018), dengan memahami pola-pola di setiap kesempatan dalam strategi bisnis akan membawa pada kesuksesan perusahaan secara keseluruhan. Kuncinya adalah strategi yang ditetapkan harus berbeda secara luas dari unit bisnis ke unit bisnis. Tetapi untuk terciptanya segmen pelanggan pada PG Candi Baru Sidoarjo, perlunya dilakukan upgrading kapasitas dan pengurangan hari giling agar meningkatkan kualitas rendemen pada gula yang akan mempengaruhi pada jumlah produksi gula. Menurut Bantacut (2010), rendemen merupakan salah satu faktor utama dalam menghitung jumlah kristal gula yang dihasilkan, sehingga semakin tinggi randemen, maka produksi gula akan semakin meningkat.

Menurut Debrecht \& Levas (2014), pola-pola strategi bisnis yang akan membawa pada kesuksesan perusahaan. Kuncinya adalah bahwa strategi harus diciptakan berbeda secara luas dari unit bisnis ke unit bisnis lainnya, sebagai fungsi dari pertumbuhan dan posisi kompetitif relatif dari unit bisnis dan perusahaan.

Hal tersebut sesuai dengan pendapat Sulasih (2020), bahwa alternatif strategi yang dapat diterapkan oleh perusahaan adalah jika perusahaan pada posisi tanda tanya perusahaan dapat melakukan peninjauan ulang dari segi pengembangan dan penetrasi pasar ataupun divestasi. Jika pada posisi bintang maka strategi perusahaan yang dapat dipilih adalah integrasi ke belakangdepan-horizontal dan pada posisi sapi perah maka dilakukannya pengembangan produk dan diversifikasi.

\section{Simpulan}

Berdasarkan analisis Boston consulting group PG Candi Baru Sidoarjo menghasilkan posisi matrik pertumbuhan pasar terletak pada posisi tanda tanya dengan pertumbuhan pasar tergolong sangat tinggi sebesar 94\% tetapi hasil perhitungan pangsa pasar relatif rendah sebesar $0,094<1$. Maka dari itu perlu adanya peningkatan jumlah produksi dengan peningkatan kapasitas giling seiring terciptanya pasar baru dan inovasi produk dengan memanfaatkan lokasi PG Candi Baru Sidoarjo yang strategis dan didukung oleh SDM yang terampil pada penggunaan teknologi dan produk yang telah memiliki standar kualitas perdagangan, penerapan SNI dengan menerapkan aplikasi ICUMSA (International Commission for Uniform Methods of Sugar Analysis) sehingga PG Candi Baru Sidoarjo memiliki daya tawar yang kuat dalam bersaing dan berpeluang diterima di pasar baru.

\section{Pustaka}

Badan Kordinasi Penanaman Modal. 2015. Prefeasibility Study Identifikasi Peluang Investasi Pengembangan Industri Gula di Indonesia Industri Gula di Indonesia.

Badan Pusat Statistik Provinsi Jawa Timur. (n.d.). Statistik Impor Provinsi Jawa Timur 2019 (Bidang Statistik Distribusi BPS Provinsi Jawa Timur, Ed.). BPS Provinsi Jawa Timur.

Bantacut, T. 2010. Swasembada Gula : Prospek dan Startegi Pencapaiannya. Jurnal PANGAN, 19(3), 245-256.

David, F. R. 2006. Manajemen Strategis: Konsep dan Kasus (S. P \& M. H, Eds.; Ke-10). Terjamahan Dari : Concept and Cases of Strategic management.

Debrecht, D., \& Levas, M. 2014. Using the Boston Consulting Group Portfolio Matrix to Analyze Management of a Business Undergraduate Student Program at a Small Liberal Arts University. Journal of Higher Education Theory and Practice, 65-69.

Hossain, H., \& Kader, Md. A. 2020. An Analysis on BCG Growth Sharing Matrix. International Journal of Contemporary Research and Review, $11(10)$. https: / / doi.org/ 10.15520/ijcrr.v11i10.848

Kader, M. A., \& Hossain, H. 2020. An Analysis On BCG Growth Sharing Matrix. Business and Accounting Research (IJEBAR) Peer Reviewed-International Journal, 245-252. https://jurnal.stie-aas.ac.id/index.php/IJEBAR

Keelson, S. A. 2018. An Examination Of The Program Mix At Technical Universities Of Ghana: The Application Of The Boston Consulting Group Matrix. In European Journal of Business and Innovation Research (Vol. 6, Issue 1). www.eajournals.org

Maristia, K., Fitri, A., Yulistiara, E., Setianingrum, K. Y., Sanjaya, V. F., Islam, U., Raden, N., \& Lampung, I. 2020. Analisis Matriks BCG (Boston Consulting Group) dalam Strategi Mempertahankan Pangsa Pasar Pada Smartphone Merek Samsung (Studi Kasus Pada PT. Samsung Elektronik Indonesia Tahun 2019). Jurnal Ekonomika, XI, 28-45.

Mohajan, H. K. 2018. An Analysis on BCG Growth Sharing Matrix Successful Shipping Management of American President Line (APL): Local and Global Analysis View project Future of Rohingyas 
in Bangladesh View project An Analysis on BCG Growth Sharing Matrix. Noble International Journal of Business and Management Research, 02(01), 1-6.

Nugroho, N. E. 2018. Analisis Matriks Boston Consulting Group (BCG) terhadap Kinerja Sekolah Tinggi dalam Upaya Menciptakan Keunggulan Bersaing di Lingkungan Kopertis Wilayah VII Jawa Timur. Jurnal Imiah Imu-Imu Sosial Dan Humaniora, 15(1), 8-14.

Prasetyo, Y. W., \& Sunarti, E. Y. 2016. Perumusan Strategi Bisnis Perusahaan menggunakan Matriks Boston Consulting Group (BCG) dan Matriks TOWS-KP (Studi Pada PT Bank Muamalat Tbk.). In Jurnal Administrasi Bisnis (JAB)|Vol (Vol. 40, Issue 1).

Respati, A., Sekolah, P., Manajemen, T., Dan Komputer, I., Unggul, A., \& Surakarta, B. ". 2015. Analisis Matriks Boston Consulting Group (BCG) Sepeda Motor Merek Honda (Matrix Analysis of Boston Consulting Group (BCG) Brand Honda Motorcycle). Jurnal Aplikasi Pelayaran Dan Kepelabuhanan, 05(02), 139-152.

Ristianingsih, Y., Angreani, N., \& Fitriani, A. 2018. Proses Pembuatan Kertas Dari Kombinasi Limbah Ampas Tebu dan Sekam Padi Dengan Proses Soda. Chempublish Journal, 2(2).

Rusdan, H. 2016. Analisis Strategi Portofolio Produk Koperasi Simpan Pinjam (Studi Pada Koperasi Simpan Pinjam Karya Mandiri Jerowaru). Jurnal Magister Manajemen Universitas Mataram, 05(04), 1-15.

Rute, I. K., Darwanto, D. H., \& Widodo, S. 2015. Permintaan Gula Kristal Mentah Indonesia The Demand for Raw Sugar in Indonesia. Imu Pertanian, 18(1), 24-30.

Saputra, A. D. W., Danial, R. D. M., \& Samsudin, A. 2020. Analisis Strategi Pemasaran Industri Makanan Ringan Menggunakan Boston Consulting Group Matrix. JIMEK: Jurnal Imiah Mahasiswa Ekonomi, 3(1), 1. https://doi.org/10.30737/jimek.v3i1.710

Saputri, N. K. 2018. Reformasi Kebijakan untuk Menurunkan Harga Gula di Indonesia oleh. www.cips-indonesia.org

Sarjono, H., Engkos, ;, \& Kuncoro, A. 2013. Analisis Matriks Boston Consulting Group (BCG) untuk Memenangkan Strategi Organisasi (Studi Kasus Perguruan Tinggi di Kopertis Wilayah III-DKI Jakarta). In BINUS BUSINESS REVIEW (Vol. 4, Issue Mei). http://faculty.unlv.edu/phelan/Research/BCG.pdf

Shafira Puteri, F., Nuringwahyu, S., Krisdianto Jurusan Administrasi Bisnis, D., \& Kunci, K. 2019. Matriks Boston Consulting Group (BCG) sebagai Dasar Perencanaan Strategi Perusahaan (Studi Kasus Pada PT. Matahari Departement Store TBK). In JIAGABI (Vol. 8, Issue 3).

Siwi, P., \& Handojo, B. 2019. Impor Gula Mentah (Raw Sugar) Versus Swasembada Gula. Majalah Imiah Bahari Jogja, 17(2), 100-111. https://doi.org/10.33489/mibj.v17i2.214

Sulasih. 2020. Metode Boston Consulting Group (BCG) sebagai Dasar Menentukan Strategi Pemasaran Pada UD. Putra Bangun Furniture Production. Jurnal Muslim Heritage, 05(01), 133-154.

Trikuntari, D., Permadhi, D., \& Putra, L. K. 2020. Analisis Kinerja dan Prospek Komoditas Gula. Opini Dan Analisis Perkebunan, 1(1), 1-10.

Zaini, A. 2008. Pengaruh Harga Gula Impor, Harga Gula Domestik, dan Produksi Gula Domestik terhadap Permintaan Gula Impor di Indonesia. Jurnal EPP, 5(2), 1-9. 